\title{
DESINFESTAÇÃO IN VITRO DA BANANEIRA 'FARTA VELHACO (SUB GRUPO AAB)' EM DIFERENTES CONCENTRAÇÕES DE CLORO ATIVO ${ }^{1}$
}

\author{
GUSTAVO ALVES PEREIRA ${ }^{2 *}$, MARCÍLIO BOBROFF SANTAELLA ${ }^{3}$, LEFAYETE MICHELE SANTANA \\ MONTENEGRO ALVES ${ }^{4}$, ELDER CASSIMIRO DA SILVA
}

\begin{abstract}
RESUMO - A maioria dos plantios de bananeira são realizados utilizando mudas tradicionais do tipo chifre e rizomas. Outros métodos de propagação, como a micropropagação, vêm sendo desenvolvidos e aperfeiçoados com fim a elevar a taxa de multiplicação em curto espaço de tempo e melhorar a qualidade fitossanitária das mudas. Contudo, a contaminação por bactérias e fungos é um dos maiores problemas dessa técnica. O objetivo do presente trabalho foi avaliar a desinfestação in vitro utilizando concentrações de cloro ativo em explantes de bananeira 'Farta Velhaco'. O delineamento experimental utilizado foi inteiramente casualizado constituído de cinco tratamentos e cinco repetições, sendo cada uma destas representada por cinco explantes em diferentes concentrações de cloro ativo durante vinte minutos, quais sejam: T1 - testemunha sem cloro ativo; T2 - 0,5\% de cloro ativo; T3 - 1,0\% de cloro ativo; T4 - 1,5\% de cloro ativo; e T5 - 2\% de cloro ativo. Foram avaliadas as porcentagens de contaminação por bactérias e fungos, como também a porcentagem de oxidação dos explantes. Os dados foram submetidos às análises de variância e de regressão. Os resultados permitiram concluir que a maior eficiência dentre os tratamentos testados foi o de imersão dos explantes em 1\% de cloro ativo, o qual proporcionou redução em $95 \%$ e $90 \%$, respectivamente, para bactérias e fungos e $60 \%$ dos explantes oxidados. Concluiu-se que essa concentração pode ser utilizada para o controle de contaminações para micropropagação de bananeira 'Farta Velhaco'.
\end{abstract}

Palavras-chave: Musa sp.. Micropropagação. Estabelecimento.

\section{DESINFESTATION IN VITRO OF BANANA 'FARTA VELHACO’ (SUB GROUP AAB)' DIFERENTS CONCENTRATIONS ATIVE CHORO}

\begin{abstract}
Most banana plantations are still made using traditional clones per type horn and rhizomes. Other propagation methods such as micropropagation have been developed and perfected to raise the rate of multiplication in a short time and improve the health status of the seedlings. However, contamination by bacteria and fungi is one of the biggest problems of this technique. The aim was to evaluate the in vitro disinfestation using active chlorine concentrations of banana explants 'Farta Velhaco'. The experimental design used was completely randomized consisting of five treatments and five repetition, each replicate represented by five explants in different concentrations of active chlorine for twenty minutes: $\mathrm{T} 1$ - without active chlorine, $\mathrm{T} 2-0.5 \%$ active chlorine, $\mathrm{T} 3-1.0 \%$ of active chlorine, $\mathrm{T} 4-1.5 \%$ active chlorine and $\mathrm{T} 5-2 \%$ active chlorine. The percentages of contamination by bacteria and fungi as well as the percentage of oxidation of the explants were evaluated. Data were subjected to analysis of variance and regression analysis. The results showed that the highest efficiency among the tested treatments was the immersion of explants in $1 \%$ of active chlorine that caused a reduction in $95 \%$ and $90 \%$ respectively for bacteria and fungi and $60 \%$ of explants oxidation. It was concluded that this concentration can be used to control contamination for micropropagation of banana 'Farta Velhaco'.
\end{abstract}

Keywords: Musa sp.. Micropropagation. Desinfestation.

\footnotetext{
*Autor para correspondência

${ }^{1}$ Recebido para publicação em 12/08/2014; aceito em 21/09/2015.

2,3,4,5 Pesquisadores do Centro Regional de Pesquisa e Transferência de Tecnologia (EMPAER-MT), Rua Senador Jonas Pinheiro S/N, Ponte Nova, CEP: 78115-100, Várzea Grande (MT); gustavo_apereira@yahoo.com.br, marcilios19@gmail.com, lefayete.michele@gmail.com, elder_cassimiro@yahoo.com.br.
} 


\section{INTRODUÇÃO}

O Brasil é o quinto maior produtor mundial de banana com área colhida de 492.113 hectares, produzindo 7.090.619 toneladas de banana, sendo a Índia o maior produtor, com 26.996.600 toneladas. O estado de Mato Grosso apresentou área colhida de 6.789 ha, produzindo 63.942 toneladas (AGRIANUAL, 2013).

A evolução da bananicultura brasileira foi possível em virtude dos progressos obtidos no que se refere à disponibilidade de material genético diversificado, à disponibilidade de mudas sadias e de boa qualidade genética, às práticas culturais de manejo pré e pós-colheita, às técnicas fitossanitárias desenvolvidas, às técnicas de nutrição e de irrigação e à melhoria do nível técnico e organizacional do bananicultor brasileiro (LICHTEMBERG; LICHTEMBERG, 2011).

A propagação da bananeira (Musa sp.) pode ser feita de várias formas: por sementes (oriundas da sua inflorescência); ou vegetativamente por meio de mudas pelo método tradicional utilizando mudas tipo chifrão, chifre, chifrinho, fracionamento de rizoma ou in vitro. Pelo método tradicional, mesmo o material sendo de ótima qualidade, o processo é lento e permite a disseminação de doenças e pragas como Sigatoka negra, Sigatoka amarela, mal-do-Panamá, broca do rizoma e nematoides (SOUZA et al., 2006).

A utilização de técnicas modernas de biotecnologia, como a cultura de tecidos, a manipulação genética e a biologia molecular, estão sendo utilizadas para o melhoramento genético de plantas, permitindo o desenvolvimento de novas variedades. Dentre as diversas práticas de cultura de tecidos uma das mais utilizadas é a micropropagação, sendo responsável pela produção de mudas de diversas espécies com fins comerciais (PEREIRA, 2009).

O princípio básico para o sucesso da cultura de tecidos decorre das medidas de prevenção e controle da contaminação microbiana. Tudo isso em função da técnica proporcionar um ambiente favorável para o crescimento de microrganismos como bactérias, leveduras e fungos filamentosos (LEIFERT et al., 1994; SILVA et al., 2004).

$\mathrm{Na}$ fase de estabelecimento in vitro, dependendo da origem do material, a contaminação pode comprometer o trabalho de micropropagação. As porcentagens de contaminações podem variar entre as variedades. Para minimizar a contaminação microbiana inúmeros protocolos de esterilização são apresentados por diversos autores, quais sejam, o uso de substâncias como hipoclorito de sódio (PEREIRA et al, 2009) e, em alguns casos, a adição de antibióticos ao meio de cultura (PEREIRA et al., 2011).

A banana 'Farta velhaco' tipo terra é a mais plantada no Estado do Mato Grosso dentre os pequenos produtores, principalmente na agricultura familiar, tornando-se uma fonte de renda e como fixadora da família junto ao campo. Todavia, a falta de estu- dos para a micropropagação dessa variedade faz com que os produtores utilizem mudas propagadas pelo método tradicional, fazendo com que na maioria dos casos mudas infestadas com broca e nematoides sejam plantadas, permitindo com esse acesso a contaminação de áreas ainda livres. Não há relatos de trabalhos de pesquisa para micropropagação dessa variedade na bananicultura do estado do Mato Grosso, tornando o presente trabalho inédito, no qual possibilitará estabelecer no futuro um protocolo eficiente para a produção de mudas de qualidade.

Nesse ínterim, o objetivo deste trabalho foi avaliar a desinfestação in vitro de explantes de bananeira 'Farta Velhaco' utilizando concentrações de cloro ativo durante a fase de estabelecimento da cultura in vitro.

\section{MATERIAL E MÉTODOS}

O presente trabalho foi desenvolvido no Laboratório de Cultura de Tecidos da Empresa Matogrossense de Pesquisa, Assistência e Extensão Rural (EMPAER-MT), localizado no Centro Regional de Pesquisa e Transferência de Tecnologia localizado, no município de Várzea Grande (MT). Os explantes utilizados foram obtidos de plantas matrizes originadas de clones de Musa sp. 'Farta Velhaco', cultivada no Centro de Pesquisa Regional de Pesquisa e Transferência de Tecnologia da EMPAER-MT, no município de Cáceres (MT), no período de 20 de junho a 20 de julho de 2013, com espaço de 1 mês para melhor aproveitamento do meio de cultura. Após a obtenção dos rizomas, estes foram lavados para retirar o excesso de solo e raiz. Em seguida, as bainhas foram seccionadas com uma faca esterilizada, permitindo a redução de seu tamanho.

Utilizou-se água sanitária como fonte de cloro ativo (com 2,0\% de cloro ativo), tendo em vista seu baixo custo. Os tratamentos utilizados foram: T1 testemunha em água - $0 \%$ de cloro ativo; T2 - 0,5\% de cloro ativo; T3 - 1\% de cloro Ativo; T4 - 1,5\% de cloro ativo; e T5 - 2\% de cloro ativo. Todos os explantes foram imersos no cloro ativo durante vinte minutos. Este tempo de imersão foi utilizado em outros trabalhos com bananas apresentados pelos autores Costa et al (2006), Lima e Moraes (2006), Carneiro et al (2008), Souza et al (2010) e Pereira et al (2011). Os meristemas foram extraídos em condições assépticas e incubados em meio de cultura MS (MURASHIGE; SKOOG, 1962), suplementado com sacarose a $30 \mathrm{~g} \mathrm{~L} \mathrm{~L}^{-1}$ e solidificante phytagel a 2,3 $\mathrm{g} \mathrm{L}^{-1}$, com $\mathrm{pH}$ ajustado para 5,8 \pm 1 antes da autoclavagem (esterilização), a $120^{\circ} \mathrm{C}$, com $1 \mathrm{Kgf} \mathrm{cm}^{-2}$ durante vinte minutos. A fase de estabelecimento foi realizada em sala de crescimento com temperatura $25 \pm 2{ }^{\circ} \mathrm{C}$ e fotoperíodo de 16 horas de luz a uma intensidade luminosa de $30 \mu \mathrm{mol} \mathrm{m} \mathrm{m}^{-2} \mathrm{~s}^{-1}$. Os explantes foram avaliados após trinta dias contados da data de inoculação, período esse que compreende a fase 
de estabelecimento da cultura. E também avaliadas as porcentagens de contaminação por bactéria e fungo, assim como a porcentagem de oxidação dos explantes.

$\mathrm{O}$ delineamento experimental utilizado foi o inteiramente casualizado com cinco tratamentos e cinco repetições, sendo cada repetição representada por cinco frascos contendo um explante cada. Os dados foram submetidos a análise de variância utilizando-se o programa SISVAR (FERREIRA, 2010) e análise de regressão para as concentrações do cloro ativo.

\section{RESULTADOS E DISCUSSÃO}

De acordo com a análise de variância, pode-se observar que houve diferença significativa para o teste $\mathrm{F}$ entre as concentrações de hipoclorito de sódio para as variáveis percentagens de contaminação bacteriana, fúngica e explantes oxidados $(\mathrm{P}<0,05)$ (Tabela 1). A análise de regressão indicou equações de segundo grau, como melhor ajuste para todas as variáveis.

Tabela 1. Quadrados médios da análise de variância e níveis de significância referentes a porcentagem de explantes de bananeira 'Farta Velhaco' contaminados por bactéria, fungos e oxidados. Várzea Grande (MT), 2013.

QUADRADOS MÉDIOS / CARACTERISTICAS

\begin{tabular}{lccr}
\hline & $\begin{array}{c}\text { Contaminação por } \\
\text { Bacteria } \\
(\%)\end{array}$ & $\begin{array}{c}\text { Contaminação por } \\
\text { Fungo } \\
(\%)\end{array}$ & $\begin{array}{c}\text { Oxidação } \\
(\%)\end{array}$ \\
\cline { 2 - 4 } Concentrações & $5544,00^{*}$ & $5656,00^{*}$ & $864,00^{*}$ \\
\hline C.V. (\%) & 18,28 & 24,65 & 25,86 \\
\hline
\end{tabular}

* significativo a $5 \%$ de probabilidade pelo teste $\mathrm{F}$.

C.V.(\%) $=$ Coeficiente de variação.

Na concentração de $1,0 \%$ de cloro ativo fora verificado uma taxa de $5 \%$ de contaminação por bactérias (Figura 1), resultando uma baixa contaminação em relação ao tratamento com $0 \%$ de cloro ativo, em que houve $100 \%$ de contaminação.

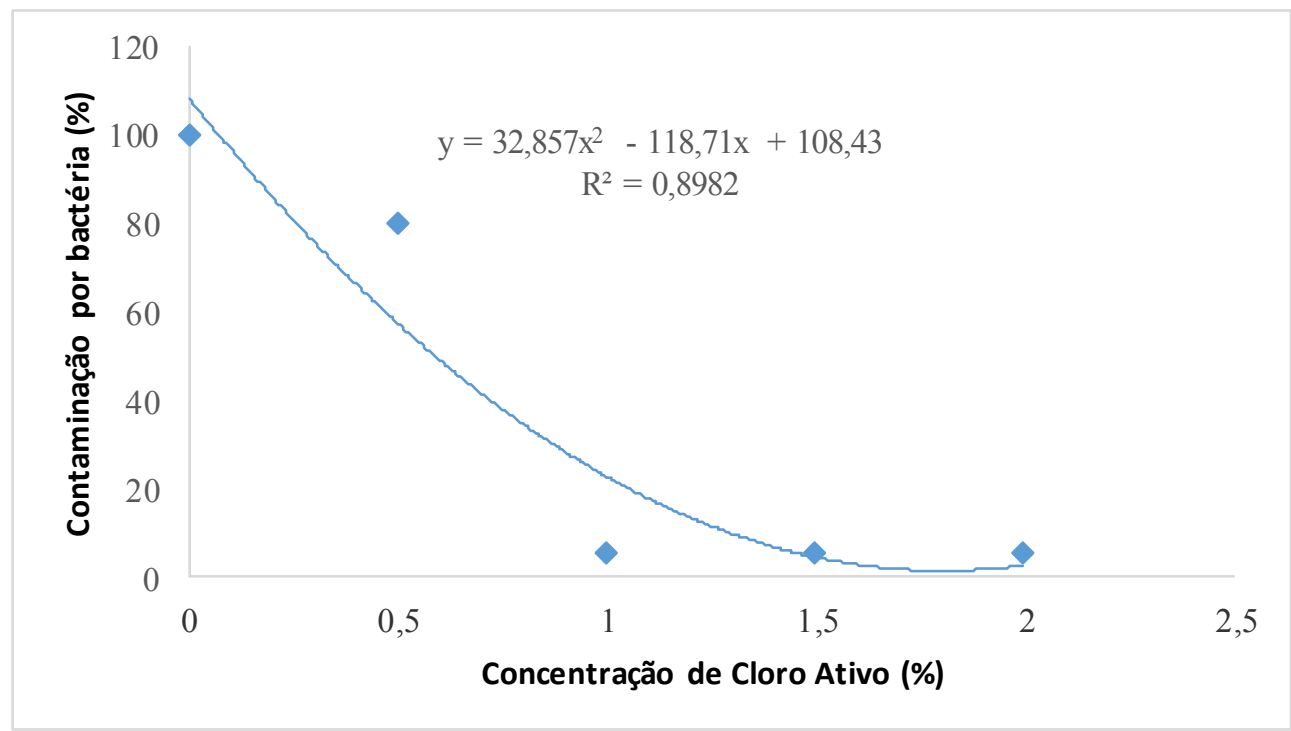

Figura 1. Porcentagem de contaminação por bactéria em explantes de bananeira 'Farta Velhaco' submetidas a diferentes concentrações de cloro ativo. Várzea Grande (MT), 2013. 
Para o controle de fungos, a concentração de $1,0 \%$ de cloro ativo proporcionou $10 \%$ de contaminantes, sendo que na concentração de $0 \%$ de cloro ativo a taxa foi de $60 \%$ de contaminação, mostrando a eficiência do cloro ativo (Figura 2).

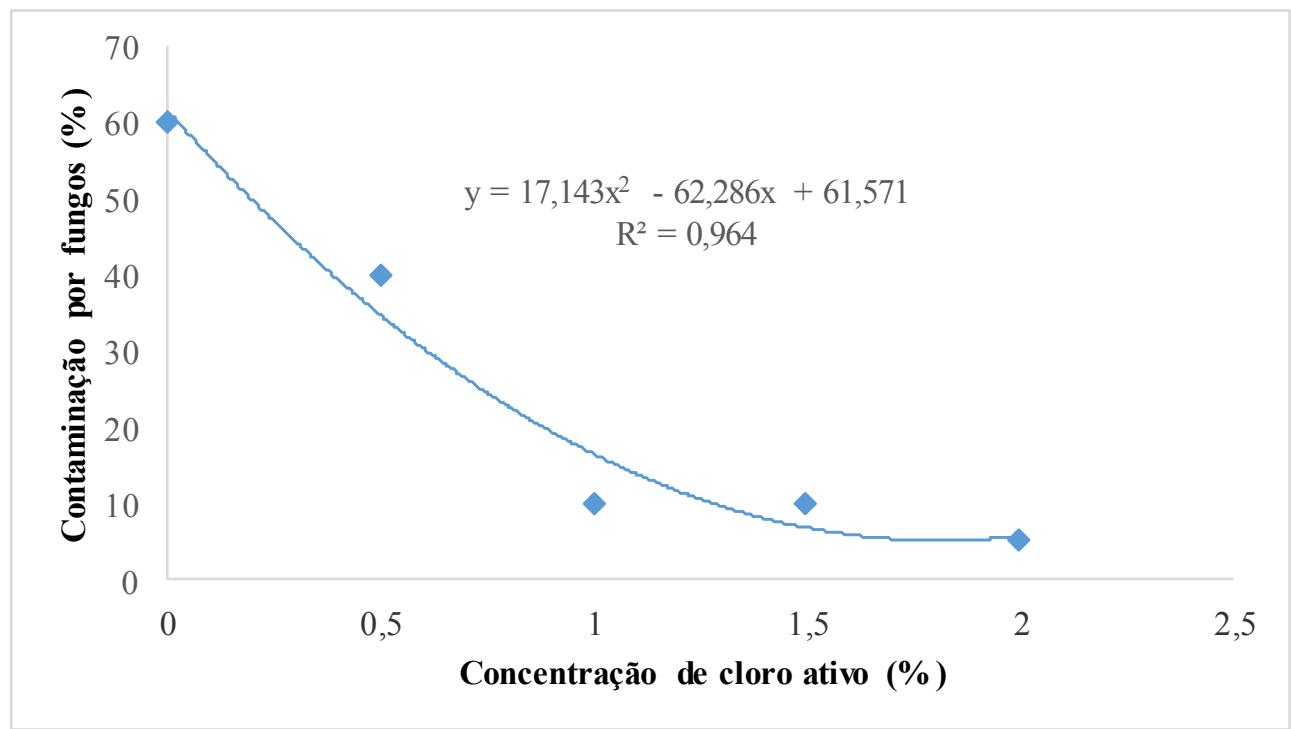

Figura 2. Porcentagem de contaminação por fungo em explantes de bananeira 'Farta Velhaco' submetidas a diferentes concentrações de cloro ativo. Várzea Grande (MT), 2013.

Em relação a oxidação, foi verificado uma taxa de $100 \%$ de explantes oxidados quando se utilizou a concentração de $2 \%$ de cloro ativo. Para a concentração de $0,5 \%$ de cloro ativo, verificou-se $10 \%$ de explantes oxidados, porém com maiores taxas de contaminantes. Na concentração de 1,0\% de cloro ativo observou-se $80 \%$ de explantes oxidados (Figura 3), porém não ocasionou a morte destes, permitindo o desenvolvimento e continuidade do processo de micropropagação. Essa oxidação ocorre naturalmente em bananas, sendo causada por compostos fenólicos.

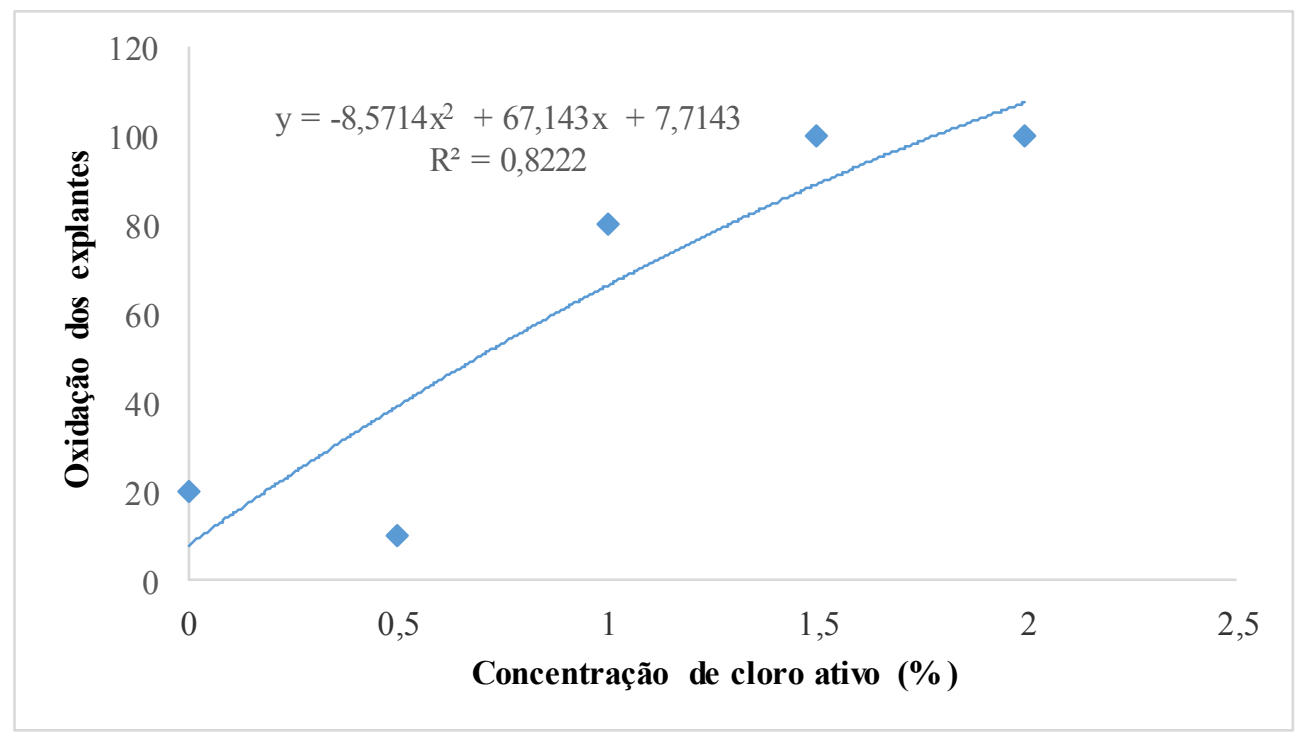

Figura 3. Porcentagem de oxidação em explantes de bananeira 'Farta Velhaco' submetidas a diferentes concentrações de cloro ativo. Várzea Grande (MT), 2013.

Os resultados de desinfestação e oxidação dos explantes encontrados neste trabalho estão de acordo com Costa et al (2006), Lima e Moraes (2006), Carneiro et al (2008), Pereira et al (2009), Souza et al (2010) e Pereira et al (2011) em trabalhos desenvolvidos com outras variedades de banana. Corroboram também com os resultados obtidos por Vianna et al (2003), os quais utilizaram como desinfestante em mamoeiro apenas hipoclorito de sódio na concentração de $1 \%$, tendo explantes com sinais visíveis de contaminação, principalmente por bactérias. Concordam também com outros autores como Picolotto et al 
(2007) que utilizaram concentrações diferentes de hipoclorito de sódio em jabuticabeira e obtiveram $2 \%$ de contaminantes utilizando hipoclorito de sódio a 5\% durante 20 minutos. Teixeira et al (2008) conseguiram desinfestação adicionando $0,005 \%$ de hipoclorito de sódio ao meio de cultura para a micropropagação de Eucalyptus pellita. Moraes et al (2007) obtiveram resultados semelhantes a este trabalho, os quais verificaram que as concentrações de 2,3 e $4 \%$ de hipoclorito de sódio reduziram a contaminação das gemas axilares em abacaxizeiro, sendo que na concentração de $2 \%$ durante 10 minutos foi a que proporcionou menor contaminação e maior sobrevivência de gemas axilares de abacaxizeiro.

Chaves et al (2004), em Prunus sp., verificaram baixo índice de contaminação em explantes tratados com hipoclorito de sódio nas concentrações $0,5 \%, 1 \%, 1,5 \%$ e $2 \%$, corroborando com os resultados obtidos neste trabalho.

Brondani et al (2013) obtiveram resultados semelhantes no estabelecimento in vitro de segmentos nodais de $E$. benthamii com concentrações menores aplicadas ao meio de cultura, sendo que as concentrações de $0,001 \%$ e $0,003 \%$ de cloro ativo com melhores resultados.

Por outro lado, os resultados conseguidos discordam de Palu et al (2011), que não obtiveram êxito com hipoclorito de sódio na micropropagação de figueira, tendo que utilizar antibióticos e obtendo melhor resultado com a adição de ampicilina sódica na concentração de $250 \mathrm{mg} \mathrm{L}^{-1}$. Costa et al (2007) obtiveram êxito utilizando uma baixa concentração de hipoclorito de sódio $(0,8 \%)$ na micropropagação de alecrim-pimenta, discordando deste trabalho ao utilizar $0,8 \%$ de cloro ativo, no qual foi possível verificar $70 \%$ de contaminantes.

\section{CONCLUSÕES}

A concentração de $1 \%$ de cloro ativo apresentou melhores resultados no controle de contaminantes e menor número de explantes oxidados.

\section{AGRADECIMENTOS}

À Empresa Matogrossense de Pesquisa, Assistência e Extensão Rural (EMPAER-MT), ao Conselho Nacional de Desenvolvimento Científico e Tecnológico (CNPQ) e à Fundação de Amparo à Pesquisa do Estado de Mato Grosso (FAPEMAT).

\section{REFERÊNCIAS}

AGRIANUAL. Anuário da agricultura brasileira. São Paulo: Instituto FNP, 2013. p. 177-188.
BRONDANI, G. E. et al. Chemical sterilization of culture medium: a low cost alternative to in vitro establishment of plants. Scientia Forestalis, Piracicaba, v. 41, n. 98, p. 257-264, 2013.

CARNEIRO, M. de F. et al. Avaliação de produtos na descontaminação de explantes de banana (Musa AAB cv. Maçã). Pesquisa Agropecuária Tropical, Goiânia, v. 30, n. 1, p. 29-35, 2008.

CHAVES, A. C; SCHUCH, M.; WALMOR, B. Desinfestação de explantes de Prunus cv. Mr. S. 2/5 com hipoclorito de sódio e cálcio. Revista Brasileira de Agrociência, Pelotas, v. 10. n. 2, p. 249-250, 2004.

COSTA A. S. et al. Estabelecimento de alecrimpimenta in vitro. Horticultura Brasileira, Brasilia, v. 25 , n. 1, p. $68-72,2007$.

COSTA, F. H. S. et al. Efeito da interação entre carvão ativado e $\mathrm{N}^{6}$-benzilaminopurina na propagação in vitro de bananeira, cv. Grand Naine (AAA). Revista Brasileira de Fruticultura, Jaboticabal, v. 28, n. 2 , p. $280-283,2006$.

ERIG, A. C.; SCHUCH, M. W. Tipo de explante e controle da contaminação e oxidação no estabelecimento in vitro de plantas de Macieira (Malus domestica Borkh.) cvs, Maxigala e Mastergala. Revista Brasileira de Agrociência, Pelotas, v. 9, n. 3, p. 221 $-227,2004$.

FERREIRA, D. F. SISVAR - Sistema de análise de variância. Versão 5.3. Lavras-MG: UFLA, 2010.

LEIFERT, C.; MORRIS, C. E.; WAITES, W. M. Ecology of microbial saprophytes and pathogens in tissue culture and field grown plants: reason for contamination problems in vitro. Critical Reviews in Plant Sciences, Netherlands, v. 13, n. 2, p. 139-183, 1994.

LICHTEMBERG, L. A.; LICHTEMBERG, P. S. F. Avanços na bananicultura brasileira. Revista Brasileira de Fruticultura, Jaboticabal, volume especial, p. 29-36, 2011.

LIMA, J. D.; MORAES, W. S. Controle de bactérias contaminantes em explantes de bananeira (Musa AAA cv. Caipira). Pesquisa Agropecuária Tropical, Goiânia, v. 36, n. 3, p. 181-186, 2006.

MORAES, A. M; ALMEIDA, F. A. C; FILHO, J. C. Desinfestação e estabelecimento in vitro de gemas axilares de abacaxizeiro. Tecnologia \& Ciência Agropecuária, João Pessoa, v. 1, n. 2, p. 39-44, 2007.

MURASHIGE, T; SKOOG, F. A. A revised medium 
for rapid growth and bioassays with tobacco tissue cultures. Physiologia Plantarum, Copenhagen, v. 15, n. 3, p. 473-497, 1962.

PALU, E. G. et al. Uso de antibióticos para o controle de bactérias endógenas visando à micropropagação da figueira. Revista Brasileira de Fruticultura, Jaboticabal, v. 33, n. 2, p. 587-592, 2011.

PEREIRA, G. A. et al. Desinfestação e estabelecimento in vitro de explantes de bananeira 'IAC 2001' em diferentes concentrações de hipoclorito de sódio. Tecnologia \& Ciência Agropecuária, João Pessoa, v. 3, n. 2, p. 43-46, 2009.

PEREIRA, G. A.; CORREA, L. S.; BOLIANI, A. C. Desinfestação e estabelecimento in vitro de explantes de bananeira 'Grande naine' em diferentes concentrações de hipoclorito de sódio. Revista Brasileira de Fruticultura, Jaboticabal, Edição Especial, p. 222-226, 2011.

PICOLOTTO, L. et al. Efeito do hipoclorito de sódio, fotoperíodo e temperatura no estabelecimento in vitro de jabuticabeira. Scientia Agraria, Curitiba, v. 8, n. 1, p. 18-23, 2007.

SILVA, J. T. S. et al. The effect of antibiotics on the in vitro growth pesponse of chrysanthemum and tabacco stem transverse thin cell layers (tTCLs). Scientia Horticulture, Netherlands, v. 97, n. 3, p. 397410, 2004.

SOUZA, A. S. et al. Introdução à Micropropagação de Plantas. 1. ed. Cruz das Almas, BA: Embrapa Mandioca e Fruticultura Tropical, 2006, 152 p.

SOUZA, D. S. et al. Micropropagação das bananeiras 'Prata-Anã' e 'FHIA 01' a partir de explantes de plantas tratadas com paclobutrazol. Revista Brasileira de Fruticultura, Jaboticabal, v. 32, n. 2, p. 561$570,2010$.

TEIXEIRA, S. L.; RIBEIRO, J. M.; TEIXEIRA, M. T. Utilização de hipoclorito de Sódio na esterilização de meio de cultura para multiplicação in vitro de Eucalyptus Pellita L. Ciência Florestal, Santa Maria, v. 18, n. 2, p. 185-191, 2008. 